\title{
Fine-scale mapping of vector habitats using very high resolution satellite imagery: a liver fluke case-study
}

\author{
Els De Roeck ${ }^{1}$, Frieke Van Coillie ${ }^{1}$, Robert De Wulf ${ }^{1}$, Karen Soenen ${ }^{2}$, Johannes Charlier ${ }^{2}$, \\ Jozef Vercruysse ${ }^{2}$, Wouter Hantson ${ }^{3}$, Els Ducheyne ${ }^{3}$, Guy Hendrickx ${ }^{3}$ \\ ${ }^{1}$ Laboratory of Forest Management and Spatial Information Techniques, Faculty of Bioscience Engineering, \\ Ghent University, Ghent, Belgium; ${ }^{2}$ Laboratory of Parasitology, Faculty of Veterinary Medicine, Ghent \\ University, Merelbeke, Belgium; ${ }^{3}$ Avia-GIS, Zoersel, Belgium
}

\begin{abstract}
The visualization of vector occurrence in space and time is an important aspect of studying vector-borne diseases. Detailed maps of possible vector habitats provide valuable information for the prediction of infection risk zones but are currently lacking for most parts of the world. Nonetheless, monitoring vector habitats from the finest scales up to farm level is of key importance to refine currently existing broad-scale infection risk models. Using Fasciola hepatica, a parasite liver fluke as a case in point, this study illustrates the potential of very high resolution (VHR) optical satellite imagery to efficiently and semi-automatically detect detailed vector habitats. A WorldView2 satellite image capable of $<5 \mathrm{~m}$ resolution was acquired in the spring of 2013 for the area around Bruges, Belgium, a region where dairy farms suffer from liver fluke infections transmitted by freshwater snails. The vector thrives in small water bodies (SWBs), such as ponds, ditches and other humid areas consisting of open water, aquatic vegetation and/or inundated grass. These water bodies can be as small as a few $\mathrm{m}^{2}$ and are most often not present on existing land cover maps because of their small size. We present a classification procedure based on object-based image analysis (OBIA) that proved valuable to detect SWBs at a fine scale in an operational and semi-automated way. The classification results were compared to field and other reference data such as existing broad-scale maps and expert knowledge. Overall, the SWB detection accuracy reached up to $87 \%$. The resulting fine-scale SWB map can be used as input for spatial distribution modelling of the liver fluke snail vector to enable development of improved infection risk mapping and management advice adapted to specific, local farm situations.
\end{abstract}

Keywords: Fasciola hepatica, liver fluke, small water body mapping, object-based image analysis, Belgium.

\section{Introduction}

Wetlands are abundant in many parts of the world. They play important roles as ecosystems in flood control, replenishment of groundwater and water purification serving as biodiversity hotspots and drinking areas for animals (Millenium Ecosystem Assessment, 2005; Cannon, 2011; Powers et al., 2012; Rey et al., 2012). Wetlands provide the habitats for many disease vectors, such as snails and mosquitoes that can infect humans or animals, with malaria, schistosomiasis and other parasitic diseases (Macpherson et al., 2000; Conlan et al., 2011; Rey et al., 2012). The life-cycle of the liver fluke Fasciola hepatica depends on the intermediate snail host Galba truncatula. The highly dynamic small water bodies (SWBs), such as ponds,

\footnotetext{
Corresponding author:

Frieke Van Coillie

Laboratory of Forest Management and

Spatial Information Techniques

Faculty of Bioscience Engineering, Ghent University

Coupure Links 653, 9000 Gent, Belgium

Tel. +32 9 264-6108

E-mail: frieke.vancoillie@ugent.be
}

ditches and wet pasture areas constitute the main habitat of this vector (Torgerson and Claxton, 1999; Schweizer et al. 2007; Charlier et al., 2011; Rondelaud et al. 2011). Knowledge of the local occurrence and dynamics of the freshwater vector habitats is hence of key importance for studying spatial variation in disease transmission.

In order to control infection, spatial distribution models of liver flukes have been developed in several regions of the world. They act as a means to increase awareness of $F$. hepatica transmission and the need for treatment/control among animal health workers and farmers. F. hepatica-infected and uninfected farms can, both within low- and high-risk areas, co-exist next to each other depending on the presence or absence of suitable SWB habitats for the principal intermediate host, G. truncatula (Bennema et al., 2009). Recent field research has shown that assessment of the presence of the intermediate host snails combined with farm management practices can be a powerful approach to predict $F$. hepatica infection risk at the farm level (Charlier et al., 2011). However, most risk assessment work to date has been done at relatively low spatial resolutions, e.g. the study by McCann et al. 
(2010) where the risk was estimated using post codes with a mean surface area of $2,000 \mathrm{~km}^{2}$. Mapping potential habitats at a finer spatial scale could substantially improve the temporal and spatial resolution of current risk maps and create novel possibilities for improved disease management based on better understanding of transmission dynamics at the local habitat scale (Lacaux et al., 2007; Simoonga et al., 2009; Charlier et al., 2011; Estallo et al., 2012). Flexible, automated and operational tools capable of characterising vector habitats at high resolutions are, however, currently lacking.

Vector habitats can be mapped by extensive ground surveys requiring considerable amounts of time, manpower and money. However, since the study of large areas by ground surveys is impractical, the use of remotely sensed imagery is a useful alternative for habitat detection. Remote sensing allows non-invasive, multi-temporal monitoring in an automated way, mapping large areas and locations that are difficult to access in the field. The use of remote-sensing techniques in wetland mapping can thus reduce costs, time and manpower.

Traditionally, wetland systems are mapped manually on aerial photography (Ozesmi and Bauer, 2002; Halabisky et al., 2011). However, manual photo interpretation is time-consuming and also very expensive for large surveys (Ozesmi and Bauer, 2002; Halabisky et al., 2011). Radar remote-sensing techniques have constraints regarding temporal resolution and operational exploitation but have the advantage of providing information under all weather conditions and can, in specific circumstances, detect water under close vegetation (Rosenquist et al., 2007). Radar altimetry offers the possibility to monitor reservoir and lake water depth in an operational manner with a high temporal resolution. However, radar imagery has limitations with regard to the minimum size of detectable objects and their location in the satellite field of view (Alsdorf et al., 2007; Reynolds et al., 2007). Recently, the use of optical satellites with very high resolution (VHR), i.e. spatial resolution of $<5 \mathrm{~m}$, has made it possible to acquire spatial accuracy at sub-meter scales thereby allowing the detection of water bodies that cover only a few $\mathrm{m}^{2}$. However, few initiatives have been undertaken to monitor SWBs using VHR satellite imagery (Dambach et al., 2009; Soti et al., 2009; Soti et al., 2010). Many studies use the freely available Landsat imagery (about 30-m resolution) and medium $(20 \mathrm{~m}$ to $100 \mathrm{~m})$ or coarse $(>100 \mathrm{~m})$ resolution imagery (Fuentes et al, 2001; Malone et al., 2001; Guo et al., 2005; Daniel et al., 2006; de Castro et al., 2006;
Estallo et al., 2012). To study the typically small liver fluke vector habitats at the farm level, however, these relatively low resolutions are insufficient.

To our knowledge, no fine-scale studies of liver fluke habitats using VHR imagery have been published, while only a few studies with $a \geq 100$-m resolution have been carried out with regard to other vectorborne diseases. Lacaux et al. (2007) have studied the zone potentially occupied by mosquitoes in a study on rift valley fever. They used the normalized difference pond index and normalized difference turbidity index based on $10-\mathrm{m}$ resolution SPOT-5 imagery (http://www.satimagingcorp.com/satellite-sensors/ other-satellite-sensors/spot-5/) to study the spatio-temporal evolution of ponds and were able to identify ponds of $100 \mathrm{~m}^{2}$ size. To study bubonic plague transferred by gerbils in Kazakhstan, Addink et al. (2010) used VHR Quickbird images (http://www.satimagingcorp.com/gallery/quickbird/) to classify gerbil habitats (burrow systems) using object-based methods. Dambach et al. (2009) studied malaria in Burkina Faso using SPOT-5 imagery at $2.5 \mathrm{~m}$ resolution and Vignolles et al. (2010) classified ponds using TerraSarX radar images (http://www.geoairbusds.com/terrasar- $\mathrm{x} /$ ) at $3-\mathrm{m}$ resolution to create an early warning system for Rift Valley Fever.

To classify SWBs, pixel or object-based algorithms can be applied (Lillesand et al., 2004). In previous reports, monitoring SWBs with VHR optical data mostly relied on the contrast between a SWB pixel and its surroundings in terms of spectral properties (Haas et al., 2009; Soti et al., 2010). Spectral analysis of the image allows for the detection of SWBs on a per pixel approach. However, since a SWB is an object of inference, object-based detection and monitoring approaches could improve detection results. Objectbased image analysis (OBIA) looks at meaningful objects within the image instead of at its individual pixels (Blaschke, 2010; Blaschke et al., 2014). OBIA provides an ideal platform combining the interpretation skills of wetland experts with computer processing power: knowledge of experienced mappers is translated into computer language by means of algorithms and rule sets (Halabisky et al., 2011). After developing and testing the OBIA rule set, it is clear that batch processing and automated processing can substantially augment classification efficiency. Due to the creation of objects, OBIA classifications are less influenced by the so-called pepper-and-salt affect (i.e. incorrectly classified individual pixels in a matrix of pixels assigned to a different land cover class) (Yu et al., 2006). Working with objects also provides the 


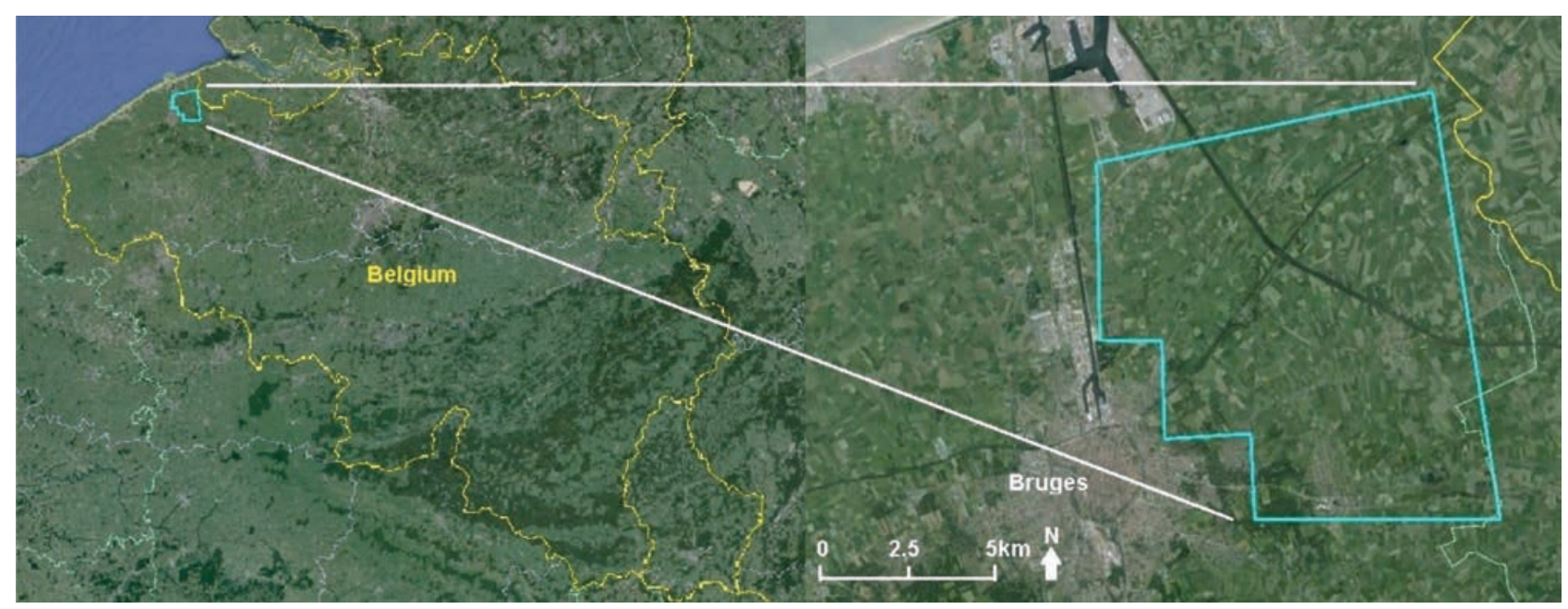

Fig. 1. Study area location (map from Google Earth).

advantage of easy incorporation in a vector-based geographical information systems (GIS) environment (Hay and Castilla, 2006; Kim et al., 2009).

The aim of this paper is to describe an automated process using VHR satellite imagery to detect SWBs at a fine spatial scale in a case study in Flanders (Bruges region) using a WorldView-2 image acquired in May 2013. The objective was to develop an automated object-based methodology to delineate SWBs and enable the identification, characterisation and classification of vector habitats. Successful results are expected to enhance the spatial resolution of epidemiological studies, resulting in an improved capacity to forecast areas under potential liver fluke threat.

\section{Materials and methods}

\section{Study area}

The study area consisted of a selection of 58 grasing fields (parcels) from 29 farms east of the historic town of Bruges in Belgium (Fig. 1). It covers mainly grasing fields and intensive, agricultural croplands. The soil is predominantly clay in the northern part and moist, loamy sand or sand in the southern part (known as the "polders") of the study area (GDI-Flanders, 2001). The landscape is characterised by being a coastal region situated in the temperate climate zone that receives on average about $800 \mathrm{~mm}$ rain per year (KMI,

\section{(a)}

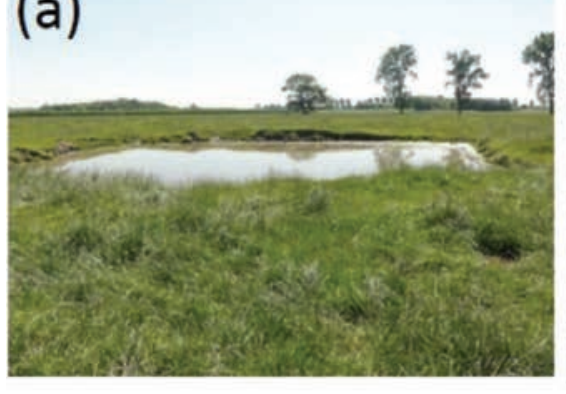

(c)

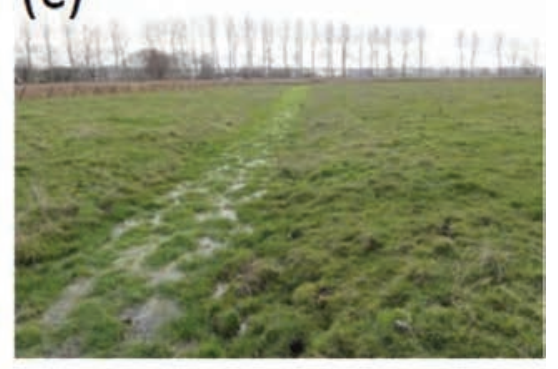

\begin{tabular}{lll}
\hline SWB type & SWB definition & Status \\
\hline Pond $(\mathrm{a})$ & Round or oval water bodies $\left(>1 \mathrm{~m}^{2}\right)$ & Permanent/temporary \\
Ditch $(\mathrm{b})$ & Elongated water bodies $\left(>1 \mathrm{~m}^{2}\right)$ & Permanent/temporary \\
Humid area $(\mathrm{c})$ & Patches with inundated terrestrial vegetation $\left(>1 \mathrm{~m}^{2}\right)$ & Temporary \\
\hline
\end{tabular}

Fig. 2. Examples of SWBs encountered in the study area. 
2013). Importantly, the area is also characterized by a high level of liver fluke infection (Bennema et al., 2011) with significant economic losses due to diminished milk production: the yearly cost for Flanders is estimated at 8.2 million $€$ or about $30 €$ per adult cow per year (Charlier et al., 2007, 2009).

The SWBs occurring in the study area are very diverse and include ponds, ditches and moist areas (Fig. 2). The SWB type definitions are not unequivocal in the literature. For this study, the SWBs with a surface exceeding $1 \mathrm{~m}^{2}$ were arbitrarily defined as round or oval ponds, while narrow, elongated water bodies were called ditches. Ponds and ditches contain open water or aquatic vegetation and can be permanent or temporary (with annual dry-out or only dry in very dry periods) normally containing inundated terrestrial vegetation (usually grass; in this article referred to as "inundated grass"). The patches trampled by cattle generally contain footprints with or without standing water. They usually lie at slightly lower altitudes than the surrounding area but still frequently dry out during periods with limited rainfall. Definition of the boundary of a water body can be challenging, even on site, and depends on researcher interpretation according to previous experience (Halabisky et al., 2011; Lyon and Lyon, 2011). In this study, the boundary of a SWB was defined as the area where no standing water is present. SWBs are dynamic systems and their boundaries hence shift over time. SWBs smaller than $1 \mathrm{~m}^{2}$ were not considered. Water troughs were also not included in this study, since these systems did not contain snails in a previous study performed by Charlier et al. (2011).

\section{Satellite imagery}

A cloud-free, Ortho-Ready Standard WorldView-2 image of the study area was acquired on 1 May 2013. The spring period was selected due to the presence of both SWBs and liver fluke snail vectors. WorldView-2 is the first commercial VHR satellite providing $8 \mathrm{spec}-$ tral sensors in the visible to near-infrared part of the spectrum: coastal blue $(400-450 \mathrm{~nm})$, blue $(450-$ $510 \mathrm{~nm})$, green $(510-580 \mathrm{~nm})$, yellow $(585-625 \mathrm{~nm})$, red $(630-690 \mathrm{~nm})$, red edge $(705-745 \mathrm{~nm})$, NIR1 (770-895 nm) and NIR2 (860-1,040 nm). Each sensor focuses on a particular range of the electromagnetic spectrum and is sensitive to particular features on the ground. Most other VHR optical satellites, such as IKONOS (http://www.satimagingcorp.com/satellitesensors/ikonos/), GeoEye (http://www.satimagingcorp.com/gallery/geoeye-1/) and Pleiades (http://www. satimagingcorp.com/satellite-sensors/pleiades-1b/) provide four multispectral bands (blue, green, red and NIR). WorldView-2's panchromatic band has a resolution of $50 \mathrm{~cm}$, while the multi-spectral bands have a resolution of $2 \mathrm{~m}$.

\section{Reference data}

Within one week from image acquisition, field reference data of about 30 SWBs known to occur in the study area were gathered. For each SWB and surrounding area, the occurrence of open water, inundated grass and aquatic vegetation was indicated on a map and detailed photographs taken. This information, land cover classes distinctly recognisable on Google Earth imagery (version 7-2013) as well as expert knowledge about the area (general layout, large-scale geographic information with respect to roads, buildings, parcels, etc.) by the Large Scale Reference dataset (GRB, 2013) were used as additional reference. The digital reference dataset was created by manually indicating single objects belonging to a given land cover class (Table 3). For each such class, a comparable number of reference samples (about 100-120 objects) was randomly specified. The purpose of the reference dataset was twofold: a random half of the dataset would be used for training the classifier, the other half for assessment of the detection accuracy (Fig. 3).

\section{Pre-processing satellite imagery}

The relative radiance values of the image were first converted to top of atmosphere reflectance values (QGIS 2.0.1). A Gram Schmidt pansharpening algorithm using cubic convolution was performed in ENVI 5.0 to convert the spatial resolution of the multispectral bands from 2 to $0.5 \mathrm{~m}$ (http://www.exelisvis.com/ Default.aspx?alias=www.exelisvis.com/envi-5\&). The image was georeferenced based on about 33 points of crossroads, road marks and other distinct features on the ground (ENVI 5.0 Classic). The reference points (accuracy of a few $\mathrm{cm}$ ) were measured with a Trimble R8 RTK GNSS receiver with Survey Controller connected to the FLEPOS RTK network of AGIV (http://www.agiv.be/ gis/diensten/flepos) in combination with several points of the GRB database (GRB, 2013). To limit computational costs, a mask was created using ArcGIS 10.1 (ESRI; Redlands, CA, USA) to extract all pastures and grasing fields of 20 study farms (surrounded by a buffer-area of $20 \mathrm{~m}$ to include adjacent water bodies). The selection of the pastures was based on the "Digital map parcels, Flanders" dataset, which maps all agricultural activities in the area (ALV, 2012). 


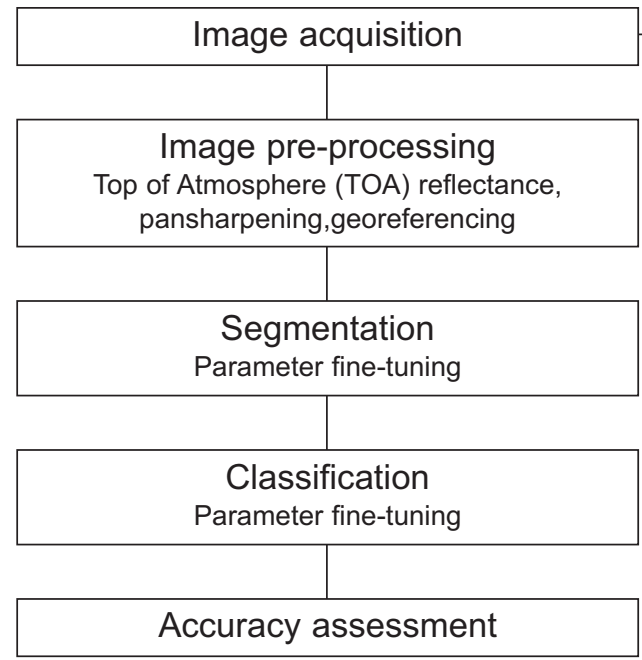

Fig. 3. Outline of study procedures.

\section{Indices and ratios}

Indices can be used as proxies for certain features on the ground, e.g. vegetation or water, to enhance classification results. Based on information gathered from other studies on water bodies (Lillesand et al., 2004; Soti et al., 2009, 2010; Wolf, 2010), the following indices were created and explored in view of SWB delineation: the normalised difference water index $(\mathrm{NDWI})=($ coastal blue $-\mathrm{NIR} 2) /($ coastal blue + NIR2), the standing water index $(\mathrm{SWI})=$ (blue NIR1)/(blue + NIR1) and the normalized difference vegetation index $(\mathrm{NDVI})=(\mathrm{NIR} 1-\mathrm{red}) / \mathrm{NIR} 1+$ red $)$. These indices, together with the hue (red, green, blue) transformation, were incorporated in the analysis.

\section{Object-based classification}

OBIA of the VHR WorldView-2 image was performed to set up an operational, semi-automatic, mapping workflow (Definiens' cognition network language $(\mathrm{CNL}))$ using the eCognition Developer 8 programme (http://www.ecognition.com/products/ecognition-developer). OBIA typically includes two steps: segmentation and classification. A segmentation algorithm creates contiguous regions in input space. The image was segmented into relatively homogeneous and semantically different groups of pixels (objects) using the multi-resolution segmentation algorithm (Baatz and Schäpe, 2000). The resulting objects (or segments) are homogeneous in terms of the phenomenon under investigation (e.g., open water bodies). Objects have the advantage that they are not only characterised by their spectral signature, but also by their shape, size, texture and context (relation to neighbouring objects) (Hay and Castilla, 2006; Blaschke, 2010). These features are extremely relevant for classification purposes and are lacking within traditional pixel-based classification methods (Hay and Castilla 2008; Blaschke, 2010). Assigning a larger weight to particular layers increases the influence of these layers on the segmentation boundaries (Aguirre-Gutierrez et al., 2012). In consequence, the bands and indices that typically show a good distinction between water bodies and other landscape elements (NDWI, NDVI, NIR1, NIR2, PAN) were given a larger weight in the segmentation process (a weight of 4 instead of 1 for all other layers).

The multi-resolution, segmentation algorithm uses scale, shape and compactness parameters. A higher scale parameter results in the creation of larger and less homogeneous objects (eCognition, 2013). The shape factor determines the influence of object shape in relation to colour. The compactness factor controls for the smoothness of the objects borders (eCognition, 2013). The ESP Tool selected the most suitable scale parameter based on the PAN band (Dragut et al., 2010), while the shape and compactness parameters were determined by a trial-and-error approach and visual interpretation of the results (similar to the procedure followed by Im et al. (2008), Halabisky et al. (2011) and Aguirre-Gutierrez et al. (2012)). The optimal scale (14), shape (0.5) and compactness (0.5) parameters were chosen in such a way that no undersegmentation occurred. As a result, each distinct SWB was characterised by one or more objects. Instant segmentation of an object covering a whole SWB was in most cases not possible. Many SWBs include inter- 
changing land cover classes. A pond can, for example, gradually change at very small scales from open water to aquatic vegetation to inundated grass land. Different land cover classes and types needed to be segmented and classified as separate objects because their spectral characteristics differed too much. Otherwise, segmentation would have been hampered, ultimately diminishing detection accuracy. The already classified land cover classes can later be merged to form distinct SWBs.

Once the optimal segments had been created, the image objects were classified using the "random tree" classifier in eCognition Developer 8 (http://www.ecognition.com/sites/default/files/eCognition $\% 20 v 8$ Datasheet.pdf) into the land cover classes water, green/dry aquatic vegetation (mainly reed), inundated grass, dry grass, shadow, shadow artefact, built-up land, soil and trees. Half of the reference data were used to automatically and iteratively train the classifier. A loop selected the optimal classification parameters (tree depth $=13$ to 22 and sample counts $=1$ to 5 with tree depth $=$ the levels of the classification tree and sample count $=$ the number of randomly sampled input features used to build the tree). To limit computational costs, this loop was run on a subset of the image covering about half of the study area. The classifier was trained on a selection of the spectral and textural features of the reference data, determined by feature space optimisation and visual assessment of the reference data (for more information on texture measures, see Haralick et al., 1973; Tso and Mather, 2009; eCognition, 2013). The following object features were included: mean and standard deviation of all image bands and indices, mean brightness, minimum and maximum pixel value (within each object) of NIR1, NIR2, NDVI and NDWI, colour saturation (RGB) and several grey-level co-occurrence matrix (GLCM) texture measures (homogeneity, contrast, dissimilarity and entropy).

The classification outcome was compared using the average user's and producer's accuracy. The producer's accuracy reflects the proportion of sample points correctly classified as $X$ over the number of points observed to be $X$; the user's accuracy reflects the proportion of sample points correctly classified as $X$ over the number of points predicted to be $X$. The difference between producer's and user's accuracy is the difference between defining accuracy in terms of how well the landscape can be mapped (producer's accuracy), versus how reliable the classification map is to the user (user's accuracy) (Congalton and Green, 2009). The three best classification results of the land cover classes water, inundated grass and aquatic vegetation, were studied visually to select the best classification result (tree depth $=14$; sample counts $=5$ ).

\section{Post-processing steps}

Contextual relationships, shape and size features were added to improve final classification of the land cover classes in a semi-automatic way. For example, the classifier did not always distinguish water from shadow very well due to similar spectral characteristics. Shadow mostly occurred next to trees. Proximity of trees was hence used to eliminate these classification errors. After merging adjacent objects belonging to the same land cover class, object size could also give an indication of classification errors. Very small isolated aquatic vegetation patches (less than 16 pixels) embedded in dry grass objects were most likely erroneous classifications and were hence merged with the land cover class "dry grass". Similar processes were used for SWB typology assessment, i.e. ponds were round or oval objects, while ditches were elongated.

\section{Accuracy assessment}

Half of the reference dataset was used to validate the classification results and determine detection accuracy. The user's and producer's accuracy, the Kappa Index of Agreement (KIA) and the overall accuracy were assessed. The producer's accuracy indicates whether the reference data were classified into the correct land cover class (omission or exclusion error). The user's accuracy (commission or inclusion error) indicated the probability that the reference data, classified to a certain class, actually belonged in real life to this land cover class. KIA takes into account the agreement that occurs by chance. The overall accuracy is a measure for the amount of correctly classified reference data (Lillesand et al., 2004; Congalton and Green, 2009).

\section{Results}

The image was classified into the land cover classes water, green aquatic vegetation, dry aquatic vegetation, inundated grass, dry grass, shadow, shadow artefact (i.e. edge between shadow and other land cover classes), built-up land, soil and trees. Fig. 4 illustrates the mean NDVI, NDWI, NIR1 and NIR2 values of the reference data for each class. An example of the OBIA process is shown in Fig. 5. The land cover classes "green" and "dry aquatic vegetation" were merged because they both represent aquatic vegetation; the 
classification accuracies for each SWB class are described in Table 1. The overall accuracy was 0.87 and overall KIA 0.71. Classification of aquatic vegetation was difficult, since most of it was comprised of dead reed at the beginning of May, which was easily misclassified as trees.

For each of the 20 farms under study, the number of SWBs, absolute SWB area $\left(\mathrm{m}^{2}\right)$ and SWB coverage (\%) were calculated (Fig. 6).

All objects classified as open water, aquatic vegetation and inundated grass were further classified for SWB typology assignment into wet area, pond and ditch (Table 2). These classifications were based on specific features, such as roundness and length/width ratio. The overall accuracy was 0.88 and overall KIA 0.59 . Table 3 summarises the error matrix of SWB typology classification. A SWB map was generated, excluding SWBs smaller than $1 \mathrm{~m}^{2}$ (4 pixels) (Fig. 6).
Table 1. Error matrix describing the accuracies of the classification of some important landcover classes.

\begin{tabular}{lccc}
\hline & $\begin{array}{c}\text { User } \\
\text { accuracy }\end{array}$ & $\begin{array}{c}\text { Producer } \\
\text { accuracy }\end{array}$ & $\begin{array}{c}\text { Kappa Index } \\
\text { of Agreement }\end{array}$ \\
\hline Water & 0.88 & 0.89 & 0.88 \\
Inundated grass & 0.84 & 0.74 & 0.72 \\
Aquatic vegetation & 0.62 & 0.60 & 0.58 \\
Other land cover classes & 0.91 & 0.92 & 0.70 \\
\hline
\end{tabular}

\section{Discussion}

This study provides a semi-automatic operational workflow for vector habitat mapping at the farm level using VHR satellite imagery. Overall the small water body detection accuracy reached $87 \%$. Even inundated grass patches, which are likely to be missed in
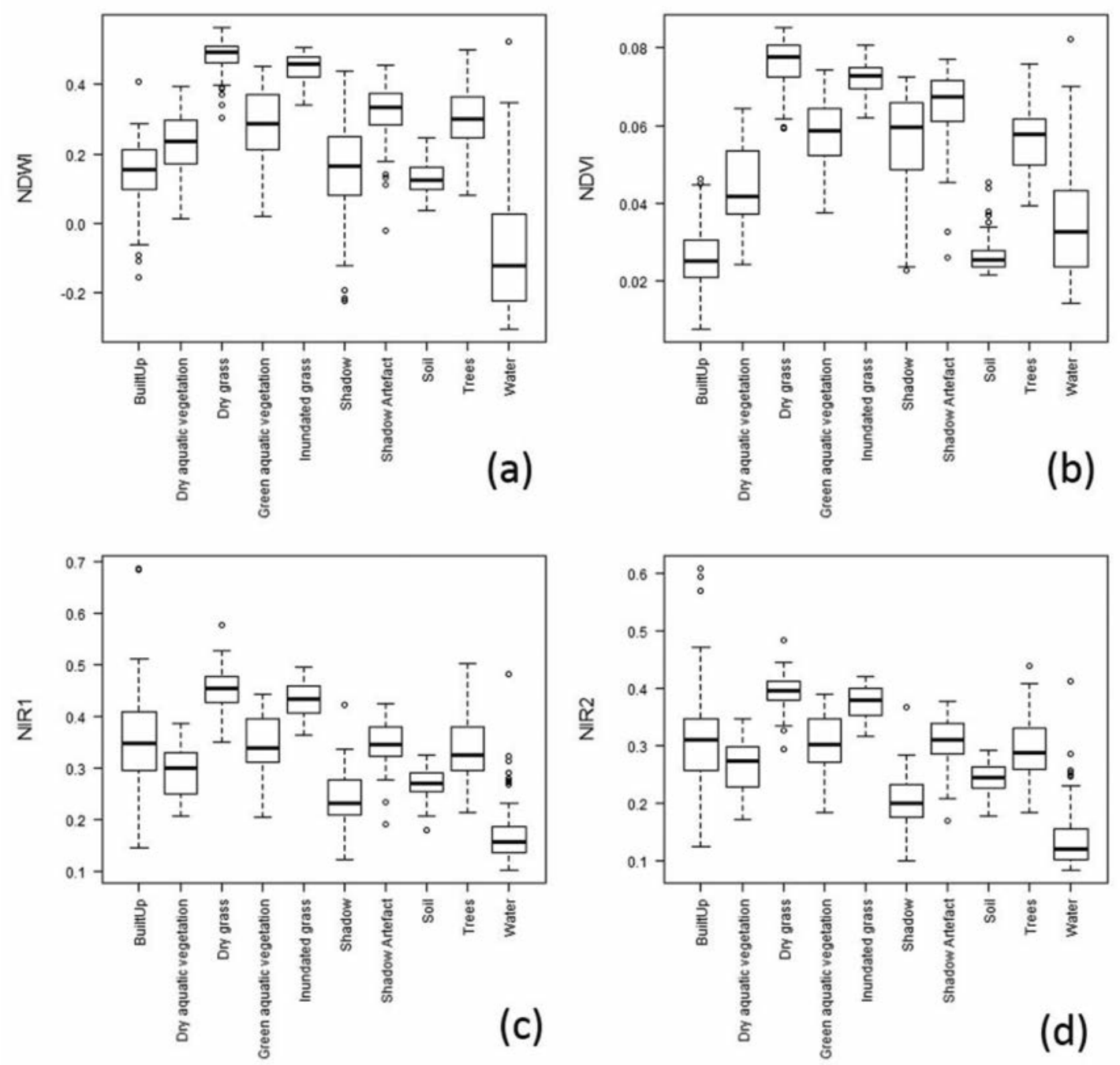

Fig. 4. Boxplots of of the reference objects for each land cover class under study based on the mean spectral value of all pixels within each reference object. (a) NDWI; (b) NDVI; (c) NIR1; (d) NIR2. 


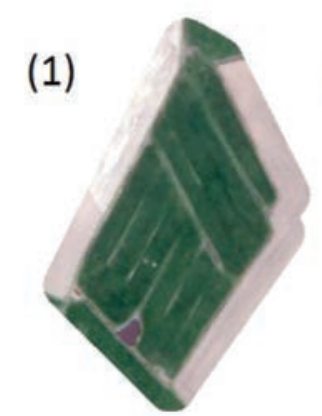

(2)

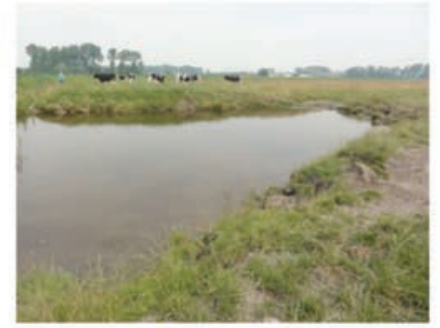

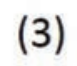

(3)

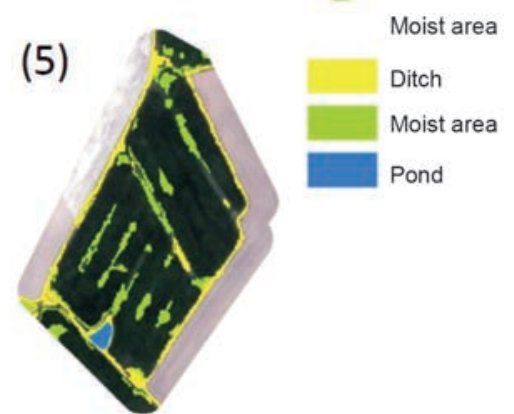

Fig. 5. OBIA process performed at the parcel-level. (1) original WorldView-2 image; (2) field picture of one of the SWBs (pond); (3) segmentation; (4) classification land cover classes (background NDWI); (5) SWB typology assigment (background RGB).

ground surveys due to visibility problems, were detected with a producer's accuracy of $74 \%$ and a user's accuracy of $84 \%$, mostly owing to the availability of near-infrared spectral information. The same procedure can potentially be used for other vectors and habitat types and may eventually lead to improved disease management for other diseases.

The scale at which vector-borne diseases are studied depends on the research question. Based on results from a large-scale study, farms with and without liver flukes can co-exist next to each other within a high infection risk zone (Bennema et al., 2009). Inclusion of fine-scale information on vector habitats and farm management could reveal an explanation for this pattern. Using remote-sensing techniques, vector habitats can be classified over a large area at a very high resolution and at different moments in time. In our case study, SWBs larger than $1 \mathrm{~m}^{2}$ were classified revealing the location of vector habitats in great detail (Fig. 5). The resulting habitat map, exported as a raster or vector layer, can be included in spatial distribution vector models. However, the classification results can also generate other interesting information, e.g. the results can be incorporated into a GIS framework while statistics with regard to area and SWB coverage can be acquired per parcel or per farm (Fig. 6). Our results show that the extent of open water is quite limited for all farms. Some farms have more aquatic vegetation or inundated grassland than others. This indicates that there are large differences between farms with regard to their suitability as potential habitat of the intermediate snail vector, most probably leading to differences in infection risk for grasing cattle.
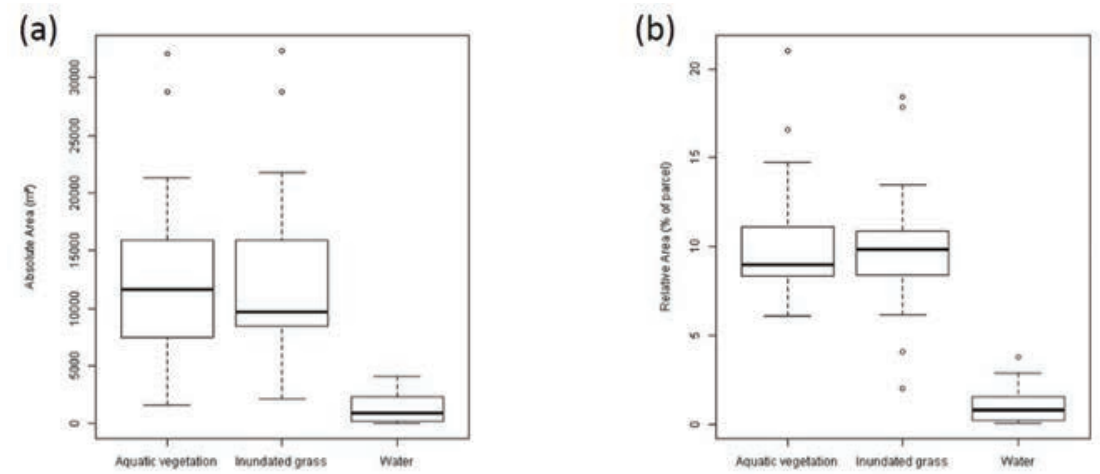

Fig. 6. Boxplot of the SWB landcover classes in each farm. (a) absolute SWB area $\left(\mathrm{m}^{2}\right)$; (b) coverage (relative area). 
Table 2. Overview of the landcover classification chain.

\begin{tabular}{lll}
\hline Classified land cover & Merged to & Post-classified into \\
\hline Water & Open water & Pond / Ditch \\
Green aquatic vegetation (mainly reed) & Aquatic vegetation & Pond / Ditch \\
Dry aquatic vegetation (mainly reed) & Aquatic vegetation & Pond / Ditch \\
Inundated grass & Inundated grass & Wet area \\
Dry grass & Other & \\
Shadow & Other & \\
Shadow artefact & Other & \\
Built-up land & Other & \\
Soil & Other & \\
Trees & Other & \\
\hline
\end{tabular}

Advantages and disadvantages of VHR satellite imagery in vector-borne disease studies

Using VHR satellite imagery for vector habitat mapping has several advantages. No extensive ground surveys are needed for manual habitat delineation, while inaccessible areas can also be studied. VHR satellite images can cover a large area at one period in time. A mosaic covering the entire area of Flanders can be acquired through combining images obtained in a few consecutive days. Since most VHR optical satellites cover the light spectrum from blue (in the case of WorldView-2, even coastal blue) to near infrared, thus delivering more information than what can visually be perceived. In addition, the creation of indices (for example NDVI) can enhance spectral characteristics and improve classification results. However, there are also disadvantages of using VHR satellite data for vector habitat detection. These images are large and a powerful computer is needed for the analysis. A multispectral WorldView-2 image of $100 \mathrm{~km}^{2}$ has a data storage requirement of about $500 \mathrm{Mb}$. The segmentation and classification algorithms needed for the analysis require over 6 hours to run by a computer with a 64 bit operating system (e.g. Windows 7) and 16 Gb RAM (e.g. Intel Core i7-2600 with a CPU running at $3.4 \mathrm{GHz}$ ). Most VHR satellite data are optical and hence, by definition, dependent

Table 3. Error matrix describing the classification accuracy with regard to SWB type.

\begin{tabular}{lccc}
\hline SWB type & $\begin{array}{c}\text { User } \\
\text { accuracy }\end{array}$ & $\begin{array}{c}\text { Producer } \\
\text { accuracy }\end{array}$ & $\begin{array}{c}\text { Kappa Index } \\
\text { of Agreement }\end{array}$ \\
\hline Pond & 0.74 & 0.97 & 0.97 \\
Ditch & 0.41 & 0.42 & 0.38 \\
Wet area & 0.79 & 0.33 & 0.31 \\
\hline
\end{tabular}

on the weather conditions. Many areas over the world are often clouded, restricting acquisition of a clear imagery. In the case of the WorldView-2 image under study, the acquisition window (maximum 10\% clouds) needed to be run from 14 April 2013 to 28 May 2013. Frequent monitoring over large regions is also hampered by the revisit time of the satellite. WorldView2 has a revisit time of 1.1 days, but due to possible cloud coverage a much larger acquisition window is often required.

Besides image acquisition, field reference data have to be gathered at around the same time that the image is taken. Depending on the size of the study area the collection of these data could take a long some time. For our study area of $100 \mathrm{~km}^{2}$, field reference data collection took about a day. To select $a$ priori accessible reference areas to be visited on the ground, the researcher can prepare an itinerary based on Google Earth imagery and expert knowledge.

In recent literature, analysis of VHR imagery for land cover mapping is most often performed by means of object-based classification. For VHR imagery such a strategy is considered to generally obtain better results than a pixel-based classification strategy (Blaschke, 2010; Dragut et al., 2010; Johansen et al., 2010). Objects provide valuable information regarding texture, shape, context and spectral characteristics (for example mean and standard deviation of the NDWI). OBIA employs elements that are traditionally used in aerial photo interpretation. The technique mimics how humans interpret imagery: through colour, shape, size, texture, pattern and contextual data (Laliberte et al., 2012). Pixel-based analyses lack most of this information. In addition, classification accuracy can be relatively low for certain land cover classes, depending on image quality, availability of good reference data and characteristics 
of the land cover classes under study. Detection of aquatic vegetation is for example more difficult than open-water detection. Moreover, surface areas underneath tree canopies cannot be detected with optical imagery.

VHR satellite imagery costs can be considerable; the WorldView-2 acquisition cost of an area of $100 \mathrm{~km}^{2}$ is about $3.000 €$ (with educational reduction). In the case of WorldView-2 imagery, acquisition costs of small areas are identical, while larger areas are more expensive. Lower resolution images from other satellite systems cost less, or are even free of charge (e.g. the Landsat advanced very high resolution radiometer (AVHRR) and the moderate resolution imaging spectroradiometer (MODIS) onboard the Terra and Aqua satellites). Many countries have a treasure of information regarding their landscapes. Areas of interest can be selected using these governmental data layers. Once the object-based rule set is developed it generates a semiautomatic image segmentation and classification procedure. It can, providing a few modifications (e.g. parameter tuning), be applied for other images as well. This creates the possibility to analyse large areas comprising of several images (county or even country level) in a semi-automated way. Of course, limited reference data have to be gathered to obtain reliable classification results and the pre-processing steps are requisite.

\section{Future perspectives}

SWB classification can be further improved by multi-temporal data analysis (Ozesmi and Bauer, 2002). In winter, none or much less aquatic vegetation is present. Since classification of open water has typically a higher accuracy than that of aquatic vegetation, combining classification of a winter image with a summer one can remove erroneous classifications carried out during summer. Using only winter imagery is not useful in the case of a liver fluke study, as the snail vector is inactive during the winter months. Since vector abundance shows seasonal peaks (spring and summer) and is strongly influenced by SWB dynamics, inclusion of multi-temporal classification results could extend and improve spatial distribution model output. Once the spatial distribution of the vector is modelled, inclusion of additional information such as farm management could provide to a useful risk model.

Inundated grass is one of the typical habitats of the liver fluke vector. Whether these areas are inundated or dry depends strongly on local weather conditions (personal observation). Detailed study of the dynamics of these inundations cannot be acquired through clas- sification of VHR satellite imagery due to the relatively long image acquisition window needed. In this respect, propeller-based unmanned aerial systems (UAS) provide a promising new remote-sensing approach for habitat detection with a high temporal and spatial resolution (Laliberte and Rango, 2009). Researchers must consider the advantages and disadvantages of each sensor type and base their image choice on the size of the study area, the land classes under study, the frequency of image collection and the required spatial and temporal resolution of the classification result.

The methodology presented in this paper is not only applicable in the field of veterinary parasitology. The importance of remote sensing for water body inventory and monitoring was already emphasised several times by the Ramsar Convention on Wetlands and confirmed by several studies (Finlayson et al., 1999; Lowry and Finlayson., 2004; Klemas, 2011). In many parts of the world, small permanent and temporary wetlands are abundantly present in the landscape (Halabisky et al., 2011). Ponds, for example, outnumber lakes by a ratio of 100 to 1 (Oertli et al., 2005). Detailed monitoring of these small systems is valuable in view of biodiversity and conservation. To our knowledge, wetland classification is in most studies limited to mapping units larger than about $100 \mathrm{~m}^{2}$ (e.g. 0.02 hectares) and often $200 \mathrm{~m}^{2}$ or larger (Halabisky et al., 2011). However, many water bodies are smaller, but nonetheless important for endemic or endangered species as they can serve as refuges or "ecological stepping stones" (Saura et al., 2014) in landscapes disturbed by humans (Céréghino et al., 2008).

\section{Conclusions}

SWBs on parcels near Bruges have successfully been detected using VHR World-View2 imagery and OBIA classification methods. Our results indicate that remote sensing techniques can be an asset in parasitological research: vector habitats can be detected at a high spatial resolution investigation of a large area in a semi-automated way. Inclusion of this spatially detailed information at the farm level can improve risk mapping for infections, and hence risk management. Nevertheless, in order to develop an operational remote-sensing tool, VHR image acquisition should be tuned to the annual G. truncatula life-cycle. Ideally, images should be cloud-free and acquisition should occur at the time of seasonal peaks in vector abundance of both adults (spring and summer) and juveniles (October/November). 


\section{Acknowledgements}

We would like to acknowledge the Belgian Science Policy Office (STEREO II Programme) and the Steering Committee of this project, ALV (Agentschap voor Landbouw en Visserij), AGIV, Geography Department of the University of Ghent (Timothy Nuttens and Alain De Wulf) and the farmers for allowing us to visit their property. We would also like to thank Dirk Tiede for help regarding the ESP tool.

\section{References}

Addink EA, De Jong SM, Davi SA, Dubyanskiy V, Burdelov LA, Leirs H, 2010. The use of high-resolution remote sensing for plague surveillance in Kazakhstan. Remote Sens Environ 114, 674-681.

Aguirre-Gutierrez J, Seijmonsbergen AC, Duivenvoorden JF, 2012. Optimizing land cover classification accuracy for change detection, a combined pixel-based and object-based approach in a mountainous area in Mexico. Appl Geogr 34, 29-37.

Alsdorf DE, Rodríguez E, Lettenmaier DP, 2007. Measuring surface water from space. Rev Geophys 45, RG2002.

ALV, 2012. Digital map parcels Flanders, Agentschap voor Landbouw en Visserij.

Baatz M, Schäpe A, 2000. Multiresolution Segmentation - an Optimization approach for high quality multi-scale image segmentation. Strobl J, Baschke T, Griesebner G (eds). Heidelberg: Wichmann-Verlag, 12-23 pp.

Bennema S, Vercruysse J, Claerebout E, Schnieder T, Strube C, Ducheyne E, Hendrickx G, Charlier J, 2009. The use of bulktank milk ELISAs to assess the spatial distribution of Fasciola hepatica, Ostertagia ostertagi and Dictyocaulus viviparus in dairy cattle in Flanders (Belgium). Vet Parasitol 165, 51-57.

Bennema SC, Ducheyne E, Vercruysse J, Claerebout E, Hendrickx G, Charlier J, 2011. Relative importance of management, meteorological and environmental factors in the spatial distribution of Fasciola hepatica in dairy cattle in a temperate climate zone. Int J Parasitol 41, 225-233.

Blaschke T, 2010. Object based image analysis for remote sensing. ISPRS J Photogramm 65, 2-16.

Blaschke T, Hay GJ, Kelly M, Lang S, Hofmann P, Addink E, Feitosa R, Van Der Meer F, Van Der Werff H, Van Coillie FMB, Tiede D, 2014. Geographic Object-Based Image Analysis - Towards a new paradigm. ISPRS J Photogramm 87, 180-191.

Cannon L, 2011. Valuing ecosystem services: the case of multifunctional wetlands. Ecol Econ 72, 189-190.

Céréghino R, Biggs J, Oertli B, Declerck S, 2008. The ecology of European ponds: defining the characteristics of a neglected freshwater habitat. Hydrobiologia 597, 1-6.

Charlier J, Bennema SC, Caron Y, Counotte M, Ducheyne E,
Hendrickx G, Vercruysse J, 2011. Towards assessing fine-scale indicators for the spatial transmission risk of Fasciola hepatica in cattle. Geospat Health 5, 239-245.

Congalton RG, Green K, 2009. Assessing the accuracy of remotely sensed data: principles and practices. CRC Press/Taylor \& Francis, 183 pp.

Conlan JV, Sripa B, Attwood S, Newton PN, 2011. A review of parasitic zoonoses in a changing Southeast Asia. Vet Parasitol 182, 22-40.

Dambach P, Sie A, Lacaux J-P, Vignolles C, Machault V, Sauerborn R, 2009. Using high spatial resolution remote sensing for risk mapping of malaria occurrence in the Nouna district, Burkina Faso. Glob Health Action 2, 149-155.

Daniel M, Zitek K, Danielova V, Kriz B, Valter J, Kott I, 2006. Risk assessment and prediction of Ixodes ricinus tick questing activity and human tick-borne encephalitis infection in space and time in the Czech Republic. Int J Med Microbiol 296, 4147.

Davidson NC, Finlayson CM, 2007. Earth observation for wetland inventory, assessment and monitoring. Aquat Conserv 17, 219-228.

de Castro MC, Monte-Mor RL, Sawyer DO, Singer BH, 2006. Malaria risk on the Amazon frontier. Proc Natl Acad Sci U S A 103, 2452-2457.

Dragut L, Tiede D, Levick SR, 2010. ESP: a tool to estimate scale parameter for multiresolution image segmentation of remotely sensed data. Int J Geogr Inf Sci 24, 859-871.

Durr PA, Tait N, Lawson AB, 2005. Bayesian hierarchical modelling to enhance the epidemiological value of abattoir surveys for bovine fasciolosis. Prev Vet Med 71, 157-172.

Dutra LH, Molento MB, Naumann CRC, Biondo AW, Fortes FS, Savio D, Malone JB, 2010. Mapping risk of bovine fasciolosis in the south of Brazil using Geographic Information Systems. Vet Parasitol 169, 76-81.

eCognition, 2013. eCognition Developer 8.9 Reference Book, Trimble Germany GmbH, Munich, Germany.

Estallo EL, Luduena-Almeida FF, Visintin AM, Scavuzzo CM, Lamfri MA, Introini MV, Zaidenberg M, Almiron WR, 2012. Effectiveness of normalized difference water index in modelling Aedes aegypti house index. Int J Remote Sens 33, 42544265.

Finlayson CM, Davidson NC, Spiers AG, Stevenson NJ, 1999. Global wetland inventory - current status and future priorities. Mar Freshw Res 50, 717-727.

Fuentes MV, 2006. Remote sensing and climate data as a key for understanding fasciolosis transmission in the Andes: review and update of an ongoing interdisciplinary project. Geospat Health 1, 59-70.

Fuentes MV, Malone JB, Mas-Coma S, 2001. Validation of a mapping and prediction model for human fasciolosis transmission in Andean very high altitude endemic areas using remote sensing data. Acta Trop 79, 87-95. 
GDI-Flanders, 2001. Digital soil map Flanders, AGIV.

GRB, 2013. Grootschalig Referentie Bestand, AGIV.

Guo JG, Vounatsou P, Cao CL, Utzinger J, Zhu HQ, Anderegg D, Zhu R, He ZY, Li D, Hu F, et al., 2009. Time series analysis of optical remote sensing data for the mapping of temporary surface water bodies in sub-Saharan western Africa. J Hydrol 370, 52-63.

Halabisky M, Moskal LM, Hall SA, 2011. Object-based classification of semi-arid wetlands. J Appl Remote Sens 5, 053511.

Haralick RM, Shanmugam K, Dinstein IH, 1973. Textural features for image classification. IEEE Trans Syst Man Cybern 3, 610-621.

Hay GJ, Castilla EA, 2006. Object-based image analysis: strengths, weaknesses, opportunities and threaths (SWOT). Obia 2006, ISPRS.

Hay GJ, Castilla EA, 2008. Chapter 1.4 - Geographic objectbaesed image analysis (GEOBIA): a new name for a new discipline. In: Lecture notes in geoinformation and cartography: object-based image analysis, spatial concepts for knowledge driven remote sensing applications. Blaschke T, S Lang S, GJ Hay GJ (eds). Berlin: Springer, 75-89 pp.

Johansen K, Arroyo LA, Phinn S, Witte C, 2010. Comparison of geo-object based and pixel-based change detection of riparian environments using high spatial resolution multi-spectral imagery. Photogramm Eng Rem S 76, 123-136.

Kim M, Madden M, Warner TA, 2009. Forest type mapping using object-specific texture measures from multispectral ikonos imagery: segmentation quality and image classification issues. Photogramm Eng Rem S 75, 819-829.

KMI, 2013. Algemeen klimaat België, KMI. Available at: http://www.meteo.be/meteo/view/nl/6042922-Algemeen+klimaat+Belgie.html (accessed on July 2013).

Lacaux JP, Tourre YM, Vignolles C, Ndione JA, Lafaye M, 2007. Classification of ponds from high-spatial resolution remote sensing: application to Rift valley fever epidemics in Senegal. Remote Sens Environ 106, 66-74.

Laliberte AS, Browning DM, Rango A, 2012. A comparison of three feature selection methods for object-based classification of sub-decimeter resolution UltraCam-L imagery. Int J Appl Earth Obs Geoinf 15, 70-78.

Laliberte AS, Rango A, 2009. Texture and scale in object-based analysis of subdecimeter resolution unmanned aerial vehicle (UAV) Imagery. IEEE T Geosci Remote 47, 761-770.

Lillesand TM, Kiefer RW, Chipman JW, 2004. Remote Sensing and Image Interpretation. New York: Wiley, 724 pp.

Lowry J, Finlayson C, 2004. A review of spatial datasets for wetland inventory in northern Australia. Darwin: Supervising Scientist Report 178, pp. 18.

Macpherson CN, Gottstein B, Geerts S, 2000. Parasitic foodborne and water-borne zoonoses. Rev Sci Tech 19, 240-258.

Malone JB, Yilma JM, McCarroll JC, Erko B, Mukaratirwa S, Zhou XY, 2001. Satellite climatology and the environmental risk of Schistosoma mansoni in Ethiopia and east Africa. Acta Trop 79, 59-72.

Malone JB, Zukowski SH, 1992. Geographic models and control of cattle liver flukes of Southern USA. Parasitol Today 8, 266-270.

McCann CM, Baylis M, Williams DJL, 2010. The development of linear regression models using environmental variables to explain the spatial distribution of Fasciola hepatica infection in dairy herds in England and Wales. Int J Parasitol 40, 1021-1028. Millenium Ecosystem Assessment, 2005. Millenium ecosystem assessment: ecosystems and human well-being: wetlands and water synthesis. Washington DC: World Resources Institute, $80 \mathrm{pp}$.

Oertli B, Biggs J, Céréghino R, Grillas P, Joly P, Lachavanne J$\mathrm{B}, 2005$. Conservation and monitoring of pond biodiversity: introduction. Aquat Conserv 15, 535-540.

Phinn S, Hess L, Finlayson CM, 1999 An assessment of the usefulness of remote sensing for wetland inventory and monitoring in Australia. Techniques for enhanced wetland inventory, assessment and monitoring. Canberra: Supervising Scientist Report 147, 44-82.

Powers RP, Hay GJ, Chen G, 2012. How wetland type and area differ through scale: A GEOBIA case study in Alberta's Boreal Plains. Remote Sens Environ 117, 135-145.

Rapsch C, Dahinden T, Heinzmann D, Torgerson PR, Braun U, Deplazes P, Hurni L, Baer H, Knubben-Schweizer G, 2008. An interactive map to assess the potential spread of Lymnaea truncatula and the free-living stages of Fasciola hepatica in Switzerland. Vet Parasitol 154, 242-249.

Rey JR, Walton WE, Wolfe RJ, Connelly CR, O'Connell SM, Berg J, Sakolsky-Hoopes GE Laderman AD, 2012. North American wetlands and mosquito control. Int J Environ Res Public Health 9, 4537-4605.

Reynolds CA, Doorn B, Birkett CM, Beckley B, 2007. Monitoring reservoir and lake water heights with satellite radar altimeters. September 17-21, Ouagadougou, Burkina Faso, Africa GIS 2007 Conference.

Rondelaud D, Hourdin P, Vignoles P, Dreyfuss G, Cabaret J, 2011. The detection of snail host habitats in liver fluke infected farms by use of plant indicators. Vet Parasitol 181, 166173.

Rosenquist A, Finlayson CM, Lowry J, Taylor D, 2007. The potential of longwavelength satellite-borne radar to support implementation of the Ramsar Wetlands Convention. Aquat Conserv 17, 229-244.

Schweizer G, Meli ML, Torgerson PR, Lutz H, Deplazes P, Braun U, 2007. Prevalence of Fasciola hepatica in the intermediate host Lymnaea truncatula detected by real time TaqMan PCR in populations from 70 Swiss farms with cattle husbandry. Vet Parasitol 150, 164-169.

Simoonga C, Utzinger J, Brooker S, Vounatsou P, Appleton CC, Stensgaard AS, Olsen A, Kristensen TK, 2009. Remote sens- 
ing, geographical information system and spatial analysis for schistosomiasis epidemiology and ecology in Africa. Parasitology 136, 1683-1693.

Soti V, Puech C, Lo Seen D, Bertran A, Vignolles C, Mondet B, Dessay N, Tran A, 2010. The potential for remote sensing and hydrologic modelling to assess the spatio-temporal dynamics of ponds in the Ferlo Region (Senegal). Hydrol Earth Syst Sc 14, 1449-1464.

Soti V, Tran A, Bailly JS, Puech C, Lo Seen D, Begue A, 2009. Assessing optical earth observation systems for mapping and monitoring temporary ponds in arid areas. Int J Appl Earth Obs Geoinf 11, 344-351.

Torgerson P, Claxton J, 1999. Epidemiology and control. In: Fasciolosis Dalton JP (ed). Wallingford: CABI Publishing, 113149 pp.

Tso B, Mather PM, 2009. Classification Methods for Remotely Sensed Data. CRC Press, 352 pp.
Tum S, Puotinen ML, Copeman DB, 2004. A geographic information systems model for mapping risk of fasciolosis in cattle and buffaloes in Cambodia. Vet Parasitol 122, 141-149.

Vignolles C, Tourre YM, Mora O, Imanache L, Lafaye M, 2010. TerraSAR-X high-resolution radar remote sensing: an operational warning system for Rift Valley fever risk. Geospat Health 5, 23-31.

Wolf A, 2010. Using WorldView 2 Vis-NIR MSI imagery to support land mapping and feature extraction using normalized difference index ratios. DigitalGlobe.

Yilma JM, Malone JB, 1998. A geographic information system forecast model for strategic control of fasciolosis in Ethiopia. Vet Parasitol 78, 103-127.

Yu Q, Gong P, Clinton N, Biging G, Kelly M, Schirokauer D, 2006. Object-based detailed vegetation classification with airborne high spatial resolution remote sensing imagery. Photogramm Eng Rem S 72, 799-811. 